\title{
SYNTHESIS AND CHARACTERIZATION OF NOVEL GIOMERS FOR DENTAL APPLICATIONS
}

\author{
IOANA HODISAN ${ }^{\mathrm{a}, \mathrm{d}}$, CRISTINA PREJMEREAN ${ }^{\mathrm{b}}$, IOAN PETEAN ${ }^{\mathrm{a}}$, \\ DOINA PRODAN ${ }^{b}$, TINCA BURUIANA ${ }^{c}$, LOREDANA COLCERIUd, \\ LUCIAN BARBU-TUDORAN ${ }^{\mathrm{e}}$, MARIA TOMOAIA-COTISEL ${ }^{\text {a,f }}$
}

\begin{abstract}
The aim of the present work was to prepare and characterize a series of dental giomers and their corresponding dental adhesive and to evaluate the adhesion of the new materials at the restoration/tooth interface. The experimental giomers were prepared as monopastes by blending the resin matrices, a new pre-reacted glass, a radiopaque glass and fluorhydroxyapatite. The novelty of the work is represented by the using of a polyalkenoic acid based on acrylic acid, itaconic acid and $\mathrm{N}$-acryloyl - Lleucine as the main component of the pre-reacted glass and of the primer in the adhesive system. In addition, the using of an original synthesized urethane tetra-methacrylate Bis-GMA analogue (Bis-GMAexp) as base monomer in the resin represents another element of novelty. The morphology of giomer samples was investigated by scanning electron microscopy. The sealing ability was tested by dye penetration method completed with atomic force microscopy investigation. The microleakage was evaluated using the score method. The results pointed out a remarkable dentin sealing for the new adhesive system and a strong adhesion at Bis-GMAexp-based giomer/ adhesive system/tooth interfaces in substantial agreement with very low value of microleakage.
\end{abstract}

Keywords: dental giomers, adhesive system, microleakage, SEM, AFM

a a Babeş-Bolyai University, Faculty of Chemistry and Chemical Engineering, 11 Arany J. str., RO-400028, Cluj-Napoca, Romania

b Babes-Bolyai University, Raluca Ripan Institute of Research in Chemistry, 30 Fantanele str., RO-400294, Cluj-Napoca, Romania

c Petru Poni Institute of Macromolecular Chemistry, lasi, Romania

d Iuliu Haţieganu University of Medicine and Pharmacy, Faculty of Dental Medicine of ClujNapoca, 8 Babeş V. str., RO-400012, Cluj-Napoca, Romania

e National Institute for Research and Development of Isotopic and Molecular Technologies, 65-103 Donath str., RO-400293 Cluj-Napoca, Romania

${ }^{f}$ Academy of Romanian Scientists, 54 Splaiul Independentei, 050094 Bucharest, Romania

*Corresponding author: cristina.prejmerean@gmail.com 
I. HODISAN, C. PREJMEREAN, I. PETEAN, D. PRODAN, T. BURUIANA,

L. COLCERIU, L. BARBU-TUDORAN, M. TOMOAIA-COTISEL

\section{INTRODUCTION}

Longevity, fluoride release and fluoride recharge abilities are crucial for the clinical performances of aesthetic dental restorative materials. Considering these requirements, during the last decade, a new class of hybrid materials which combine the chemistry of diacrylic resin composites (DRCs) with the one of the glass ionomer cements (GICs) were introduced on the market by Shofu (Kyoto, Japan). These hybrid materials were named giomers. They present long-term aesthetics and durability (which are characteristics of DRCs) as well as controllable ion release and recharge properties (which represent features of GICs).

Giomers are new restorative materials used in adhesive dentistry based on pre-reacted filler technology, where pre-reacted glass ionomer (PRG) was ground and used as fillers in a polymer matrix. PRG fillers are fabricated by acid-base reactions between fluoride containing glass and poly acrylic acid in the presence of water forming wet siliceous hydrogel.[1] Giomers are fluoride release dental materials [2] having the advantage of inhibiting dental tissues demineralization process [3].This new class of restorative materials combines the bioactivity and biocompatibility of glass ionomer with the physical and optical properties of composites offering the practitioners an excellent alternative for amalgam restoration. The giomers bond chemically to tooth structure by an intermediate adhesive system [4].

Restorative materials used in dentistry should provide a good sealing at the tooth/restorative material interface in order to prevent microleakage and postoperative complication. Adhesive systems used in restorative dentistry provide the sealing between tooth and restorative composites and should create a strong adhesive bond associated with minimal shrinkage of the resin during curing [5].

The adhesive dentistry is known to be confronted with the limitation of the dentin adhesion. That's why it is important to investigate the tooth/ adhesive system/restoration interface for the new materials in order to improve the quality of the sealing of restoration giving the opportunity of obtaining a hermetic restoration without any microleakage [6]. Microleakage was reported as the main reason for replacement of composite resin restoration [7-9]. Microleakage is usually associated with the bacterial penetration through the restoration-tooth interface, causing short-term or/and long-term clinical problems such as postoperative sensitivity, marginal staining, secondary caries, and/or pulpal inflammation and failure of endodontic treatment [10-12]. In vitro studies of microleakage are done using methods like: dye penetration method [13], measurement by scanning electron microscope [14], bacterial activity, electrochemical test, fluid filtration [15]. 
The aim of this work was to prepare and characterize a series of new giomers and their corresponding adhesive system, including the primer and the bonding. The sealing ability was tested by dye penetration method completed with AFM investigation at the interface in order to demonstrate their potential for clinical use.

\section{RESULTS AND DISCUSSION}

\section{Giomers components}

\subsection{Resins}

The experimental resins were formulated using monomer mixtures of Bis-GMAcom or an original synthesized urethane tetra-methacrylate Bis-GMA analogue (Bis-GMAexp) as base monomer and TEGDMA as diluting monomer.<smiles>CC(C)(C)C(=O)OCC(O)COc1ccc(C(C)(C)c2ccc(CC(O)C=O)cc2)cc1</smiles>

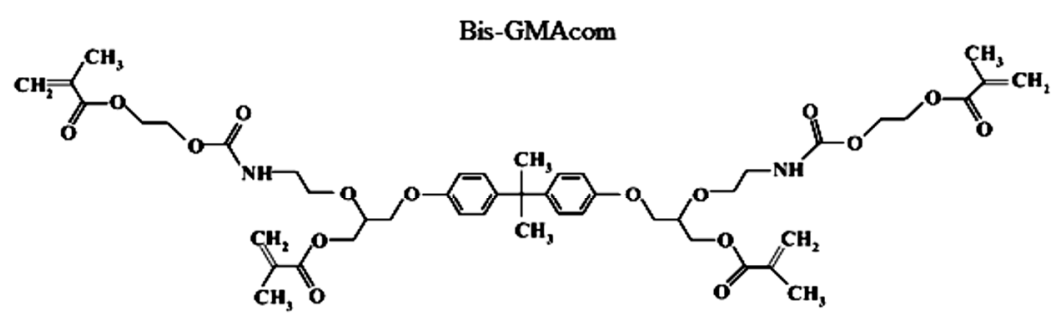

Bis-GMAexp<smiles>C=C(C)OCCOC(=O)C(=C)C</smiles>

TEGDMA

Fig.1. Chemical structures of the monomers used in this study.

The synthesis and characterization of Bis-GMAexp was presented elsewhere [16]. The ratio between the base monomer and diluting monomer was 70/30. In the composition of the resins, besides the methacrylic oligomers and monomers, a photosensitizer, camphorquinone (CQ) in an amount of $0.5 \%$ (by weight), and an accelerator N,N-dimethylaminoethyl methacrylate (DMAEMA), in an amount of $1 \%$ (by weight), were added. 


\subsection{Pre-reacted glass ionomer filler}

The experimental pre-reacted glass ionomer filler was prepared using the conventionally method employed in the preparation of traditional glass ionomer cements. PRG was prepared by hand-mixing of $50 \%$ aqueous solution of PAlk-Leu polyalkenoic acid (ternary copolymer resulted from acrylic acid, itaconic acid and $\mathrm{N}$-acryloyl-L-leucine, average molecular weight 23500 ) with the superficially active glass powder $\mathrm{G}$ having the composition: $\mathrm{SiO}_{2}(49 \%)$, $\mathrm{Al}_{2} \mathrm{O}_{3}(22 \%), \mathrm{CaF}_{2}(29 \%)$, in a weight ratio of $1 / 2.4$. After 24 hours, the PRG was dried in an oven at $95^{\circ} \mathrm{C}$ for 24 hours. Finally, it was grounded in a ball mill and sifted to fine powder.

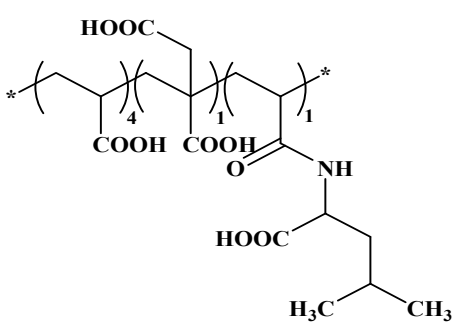

PAlk-Leu

$2 a$

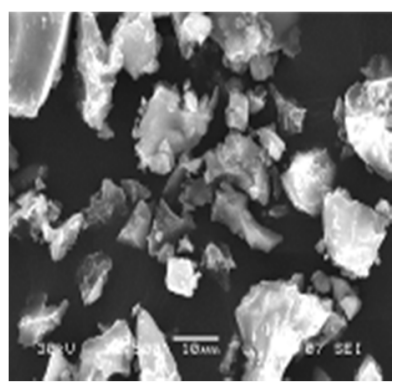

$X 1000$

$2 b$

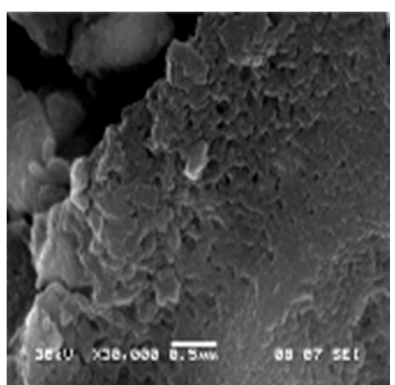

X30000

$2 c$

Figure 2. Structure of PAlk-Leu (2a; *structural unit* $)$ and SEM micrographs of the corresponding PRG $(2 b, 2 c)$

SEM images presented in Fig.2 show the morphology of the experimental PRG powder. One can observe the irregular shape of the particles with a sharp particle edges (Fig. 2b). The particle sizes showed an average diameter about $20 \mu \mathrm{m}$. The higher magnification details presented in Fig.2c reveal a porous structure of the pre-reacted glass.

\section{Giomers}

The experimental light-curing giomers were prepared as monopastes by mixing the resin matrices $(20 \%)$ with the hybrid fillers $(80 \%)$. For the obtaining of hybrid fillers, the pre-reacted glass ionomer filler (28\%) fluorohydroxyapatite $(12 \%)$, the silanized radiopaque glass powder $(40 \%)$ were mixed and then sifted together. Silanation of radiopaque glass was carried out with 3-methacryloyloxypropyl-1-trimethoxy-silane (A-174 silane). The method of obtaining and the characterization of radiopaque glass and FHAP was shown elsewhere $[16,17]$. 


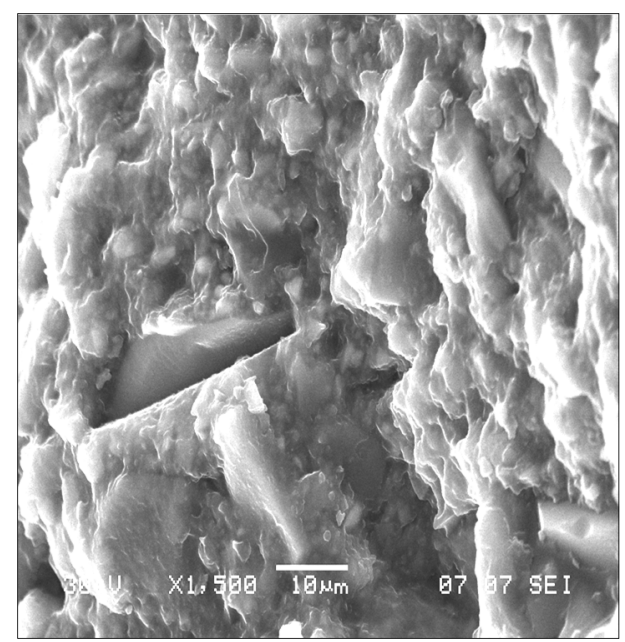

$X 1500$

$3 a$

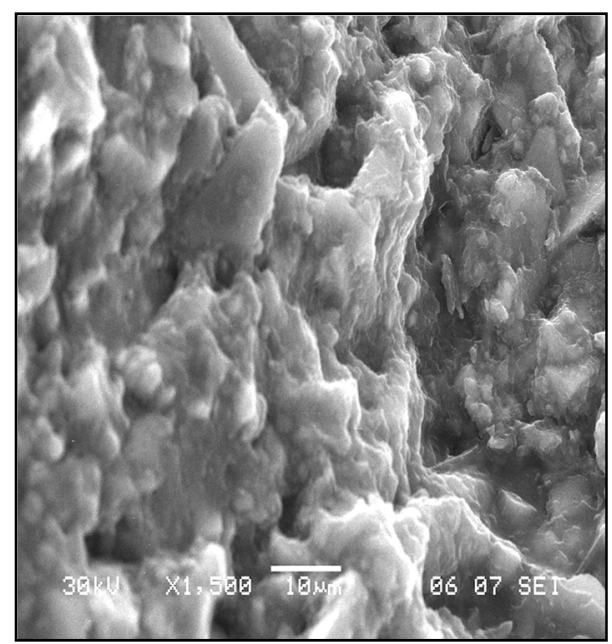

$x 1500$

$3 b$

Figure 3. SEM micrographs of the Giomer G1 (3a) and Giomer G2 (3b)

Fig. 3 shows the fracture images of Giomer $\mathrm{G} 1$ based on Bis-GMAcom (3a) and Giomer G2 based on Bis-GMAexp (3b). G1 and G2 giomers present a similar surface organization. The morphology of giomer samples is complex consisting of a high amount of fine particles well embedded in a compact polymer matrix structure. A large amount of particles measuring less than 10 microns with sharp or rounded edges (shapes) as well as a few particles having a diameter of about 20 microns can be visualized. Base on the particle size analysis, the first can be attributed to the radiopaque filler particles or small sizes PRG particles and the second ones can be attributed to the large sizes PRG filler particles [16].

\section{Obtaining of adhesive system}

The adhesive system comprising 3 components: etchant, primer and bonding (known as three-step adhesives systems) were prepared. The primer and bonding were prepared according to the method described elsewhere [26]. The composition of the adhesive system and of the G1 and G2 giomers is shown in Table 1. 
I. HODISAN, C. PREJMEREAN, I. PETEAN, D. PRODAN, T. BURUIANA,

L. COLCERIU, L. BARBU-TUDORAN, M. TOMOAIA-COTISEL

Table 1. Composition of adhesive system and of $\mathrm{G} 1$ and $\mathrm{G} 2$ giomers

\begin{tabular}{|c|c|c|c|c|c|c|}
\hline \multicolumn{2}{|c|}{ Product } & \multirow{2}{*}{\begin{tabular}{l}
\multicolumn{1}{c}{$\begin{array}{c}\text { Main } \\
\text { components }\end{array}$} \\
PAlk-Leu \\
$(30 \%)$
\end{tabular}} & \multirow{2}{*}{$\begin{array}{l}\begin{array}{c}\text { Diluting } \\
\text { monomers }\end{array} \\
\text { HEMA } \\
(32 \%) \\
\text { TEGDMA } \\
(10.7 \%)\end{array}$} & \multirow{2}{*}{$\begin{array}{l}\begin{array}{c}\text { Initiating } \\
\text { system }\end{array} \\
\mathrm{CQ} \\
(0.18 \%) \\
\mathrm{CDFI} \\
(1.12 \%)\end{array}$} & \multirow{2}{*}{$\begin{array}{c}\text { Solvents } \\
\text { Water } \\
(20 \%) \\
\text { Acetone } \\
(6 \%)\end{array}$} & \multirow{2}{*}{$\begin{array}{r}\text { Filler(s) } \\
-\end{array}$} \\
\hline $\begin{array}{l}\text { Adhesive } \\
\text { system }\end{array}$ & Primer & & & & & \\
\hline & Bonding & $\begin{array}{l}\text { Bis-GMAexp } \\
(60 \%)\end{array}$ & $\begin{array}{l}\text { HEMA } \\
(10 \%) \\
\text { TEGDMA } \\
(28.53 \%)\end{array}$ & $\begin{array}{l}\text { CQ } \\
(0.49 \%) \\
\text { DMAEMA } \\
(0.98 \%)\end{array}$ & - & - \\
\hline \multirow[t]{2}{*}{ Giomers } & $\begin{array}{l}\text { Giomer } \\
\text { G1 }\end{array}$ & $\begin{array}{l}\text { Bis-GMAcom } \\
(14 \%)\end{array}$ & $\begin{array}{l}\text { TEGDMA } \\
(5.72 \%)\end{array}$ & $\begin{array}{l}\text { CQ } \\
(0.09 \%) \\
\text { DMAEMA } \\
(0.19 \%)\end{array}$ & & $\begin{array}{c}\text { SPRG } \\
(28 \%) \\
\text { HAF }(12 \%) \\
\text { Radiopaque } \\
\text { glass }(40 \%)\end{array}$ \\
\hline & $\begin{array}{l}\text { Giomer } \\
\text { G2 }\end{array}$ & $\begin{array}{l}\text { Bis-GMAexp } \\
(14 \%)\end{array}$ & $\begin{array}{l}\text { TEGDMA } \\
(5.72 \%)\end{array}$ & $\begin{array}{l}\text { CQ } \\
(0.09 \%) \\
\text { DMAEMA } \\
(0.19 \%)\end{array}$ & & $\begin{array}{c}\text { SPRG } \\
(28 \%) \\
\text { HAF (12\%) } \\
\text { Radiopaque } \\
\text { glass (40\%) }\end{array}$ \\
\hline
\end{tabular}

\section{Determination of microleakage}

Thirty box-type Class $\mathrm{V}$ standardized cavities were prepared on premolar teeth on the facial (the face oriented in the mouth towards the cheek) and oral surfaces (the face oriented towards the tongue) of each tooth. The preparations had one margin in enamel and one margin in dentin. The preparations were divided randomly into two equal groups $(n=15)$ and restored with: group I: giomer G1 and adhesive system; group II: giomer G2 and the same adhesive system. The teeth were thermocycled, then immersed in $2 \%$ methyl blue solution for $24 \mathrm{~h}$. The specimens were sectioned longitudinal, buccolingually into slices of $1 \mathrm{~mm}$ and the resulted sections were examined for microleakage using a stereomicroscope. The extend of microleakage at the restoration/tooth interface was evaluated assessing scores: 0, 1, 2, 3 for each restoration at the enamel/restoration and dentin /restoration interface.

The microleakage behavior examined using the scoring method is presented in Table 2. 
Table 2. Microleakage scores

\begin{tabular}{|c|c|c|c|c|c|c|c|c|}
\hline \multirow{2}{*}{ Groups } & \multicolumn{4}{|c|}{ Microleakage score in dentin } & \multicolumn{3}{c|}{ Microleakage score in enamel } \\
\cline { 2 - 9 } & 0 & 1 & 2 & 3 & 0 & 1 & 2 & 3 \\
\hline I & 3 & 0 & 4 & 8 & 13 & 2 & 0 & 0 \\
\hline II & 5 & 2 & 4 & 4 & 14 & 1 & 0 & 0 \\
\hline
\end{tabular}

The results, given in table 2 , show that almost all the samples presented a minimal microleakage at the enamel margins proving that both groups of giomer restorations were sealed with the experimental adhesive system at this level and the values are comparable with the ones found in the literature for the commercials giomer materials and their adhesive systems [18-20].

The microleakage values in dentin were significantly higher than enamel values. The problem of microleakage has been largely demonstrated mainly below the cement-enamel junction in several studies [21, 22] because the bonding to dentin is far more difficult and less predictable than bonding to enamel. This behavior could be explained by the morphological differences of the tooth structures: dentin and enamel because dentin is less mineralized, about $75 \%$ as opposed to enamel which is $98 \%$. Moreover, dentin has a more complex histologic pattern, such as tubular structure and intrinsic wetness [23].

Dentin is more hydrophilic with canalicular structure with $48 \%$ vol. Hap, $29 \%$ vol. organic materials and $23 \%$ vol. water. The dentinal tubules traverse entire dentin, oriented from the dentin-enamel junction towards the pulp. This structure of dentin allows the substance to infiltrate at interface dentin/composite and to travel by water in dentinal fluid along the canalicular system towards the pulp resulting in a higher percentage of dentin microleakage than the enamel.

Between the two groups there were no significant differences concerning the microleakage value. However, it can be noticed that there were only three scores 0 for group I, while there were 5 scores 0 for group II. In addition, there were registered 8 scores 3 for group I, while were obtained only 4 scores 3 for group II.

AFM investigations were made to examine the sealing at the dentin/ adhesive system interface, which is a condition for a good restoration. The dentin surface observed by AFM microscopy is presented in Fig. 4. The topographic image, Fig. 4a, reveals the dentin tubule. Peritubular dentin is observed around the tubule in good agreement with literature data [24 - 26]. 


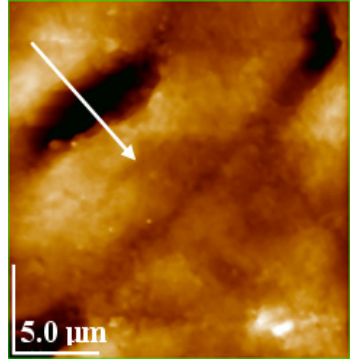

a

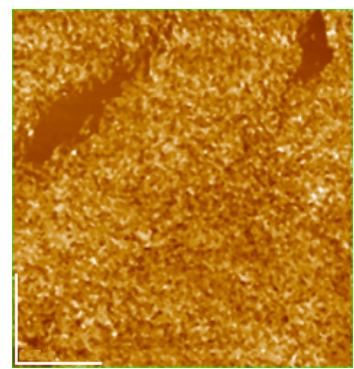

b

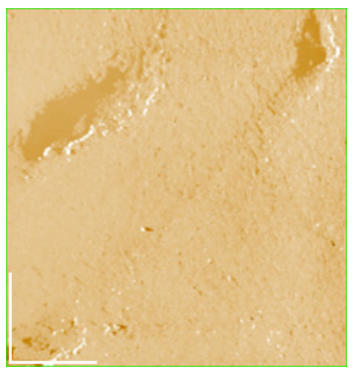

C

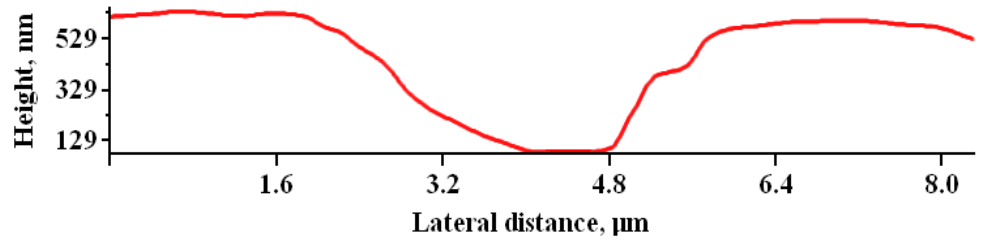

d

Figure 4. AFM images of dentin at the interface with the $\mathrm{G} 2$ giomer restoration: a) topographic image, b) phase image, c) amplitude image, d) cross section on white arrow in figure (a). Scanned area $20 \mu \mathrm{m} \times 20 \mu \mathrm{m}$.

Fig. 4c also reveals the peritubular dentin as a compact matrix having light color and the tubules appear in dark due to their depth. Cross section in Fig. 4d gives the opportunity to measure precisely the size of tubule of about $3 \mu \mathrm{m}$ [27]. The darker zone in the middle of the scanned area is the adhesive sealing the dentin surface and the tubules and thus, offering a binding with the giomer $\mathrm{G} 2$.

\section{CONCLUSIONS}

A series of dental giomers (G1 and G2) were prepared by dispersing a novel pre-reacted glass ionomer, a radiopaque glass and fluorhydroxyapatite in the resin matrices. An original synthesized urethane tetra-methacrylate BisGMA analogue (Bis-GMAexp) was used as base monomer in giomer $\mathrm{G} 2$ while commercial Bis-GMA was contained in G1 giomer. PAlk-Leu (ternary copolymer resulted from acrylic acid, itaconic acid and $\mathrm{N}$-acryloyl-L-leucine) was used as polyalkenoic acid for the obtaining of PRG and as main component of the primer in the adhesive.

The combination of adhesive system and giomer G2 performed better in terms of adhesion to the tooth structures than the same adhesive system in combination with giomer $\mathrm{G} 1$. 
We can conclude that the giomer G2 containing Bis-GMAexp could be used successfully with the experimental adhesive system based on PAlkLeu in clinical application.

\section{EXPERIMENTAL SECTION}

\section{Materials}

Reagent grade chemicals of 2,2-bis[4-(2-hydroxy-3-methacryloxypropoxy)phenyl]propane (Bis-GMA), triethyleneglycol dimethacrylate (TEGDMA), 2-hydroxyethyl methacrylate (HEMA) were purchased from Aldrich Chemical, Milwaukee, WI, USA and used without further purification. Camphorquinone (CQ), $\mathrm{N}, \mathrm{N}$-dimethylaminoethyl methacrylate (DMAEMA), diphenyliodonium chloride (CDFI) were supplied by Sigma Chemical, St. Louis, MO, USA. PAlk-Leu was synthetized by our group as reported elsewhere [28]. 3-methacryloyloxypropyl-1trimethoxy-silane (A-174 silane) were purchased from Sigma Aldrich Chemical Co. (Taufkirchen, Germany) and used without additional purification. The oxides and fluorides $\mathrm{SiO}_{2}, \mathrm{Al}_{2} \mathrm{O}_{3}, \mathrm{ZnO}, \mathrm{CaO}, \mathrm{Na}_{2} \mathrm{O}, \mathrm{B}_{2} \mathrm{O}_{3}, \mathrm{CaF}_{2}, \mathrm{BaF}_{2}$ were purchased from Merk (Darmstadt, Germany).

\section{Preparation of the adhesive system}

2.1. The experimental primer. In a round-bottomed flask equipped with a stirrer, reflux condenser and a dropping funnel $30 \mathrm{~g}$ of PAlk-Leu were introduced, and then $32 \mathrm{~g}$ of HEMA were added. The mixture was stirred at $40^{\circ} \mathrm{C}$ for $30 \mathrm{~min}$. Then $20 \mathrm{~g}$ water was dosed from the dropping funnel, and the mixture was stirred further until the complete dissolution. After about $1 \mathrm{~h}$, $10.7 \mathrm{~g}$ of TEGDMA, in which the components of the initiating system (CQ $(0.18 \mathrm{~g})$ and $\mathrm{CDFI}(1.12 \mathrm{~g})$ ) were previously added, was dosed under continuous stirring for another hour, and finally, $6 \mathrm{~g}$ of acetone was added. All operations were done in rooms protected from visible light.

2.2. The experimental bonding. $28.53 \mathrm{~g}$ TEGDMA in which the initiator system was dissolved (CQ (0.49g) and DMAEMA (0.98g)) and $10 \mathrm{~g}$ HEMA were dosed in the round-bottomed flask in which $60 \mathrm{~g}$ bis-GMA had been previously introduced. The mixture was stirred for $2 \mathrm{~h}$ at $40^{\circ} \mathrm{C}$. All operations were done in rooms protected from visible light.

\section{Preparation of the giomers}

3.1. The resin. $60 \mathrm{~g}$ of Bis-GMA type monomer (Bis-GMAcom or BisGMAexp) were introduced in a round-bottomed flask equipped with a stirrer, reflux condenser and a dropping funnel. The initiator system, (CQ $(0.49 \mathrm{~g})$ and respectively DMAEMA (0.98g), was dissolved in $29.47 \mathrm{~g}$ TEGDMA in another 
flask. After complete dissolution, the mixture was dosed under continuous stirring for two hours over the Bis-GMA monomer. All operations were done in rooms protected from visible light.

3.2. The hybrid filler. $35 \mathrm{~g}$ pre-reacted glass ionomer filler, $15 \mathrm{~g}$ fluorohydroxyapatite and $50 \mathrm{~g}$ silanized radiopaque glass powder were mixed and then sifted together.

3.3.The giomers. The experimental light-curing giomers $\mathrm{G} 1$ and $\mathrm{G} 2$ were prepared as monopastes by mixing the resin matrices with the hybrid fillers.

\section{Sample preparation}

Fifteen freshly extracted premolars for orthodontic reason were kept in distilled water at $4^{\circ} \mathrm{C}$ for 24 hours. Standardized class $V$ cavities measuring 4 $\mathrm{mm}$ length $3 \mathrm{~mm}$ width and $1.5 \mathrm{~mm}$ depth were prepared on facial and oral face of each tooth. The preparation was positioned with the gingival margin in cement (dentin) and the occlusal margin in enamel. The bur used for cavities preparation was a bur no. 4 for a high speed hand piece with water cooling system purchased from Shofu (Kyoto, Japan). The cavities were then divided randomly into 2 groups: group I cavities were restored using adhesive system and giomer G1 and group II was restored with the same adhesive system and giomer G2. The clinical protocol for the restoration included etching the cavities $30 \mathrm{sec}$ with ortophosphoric acid $37 \%$ then rinse it off and gently dry the dental tissue. Next step was applying the primer on the dentin area using a microbrush, dry it using the air spray for $3 \mathrm{sec}$ and then applying the bonding on the entire surface of the cavity. Once in place, the bonding was light-cured for $20 \mathrm{sec}$ using light-curing device Spectrum 800470 nm wavelength (Dentsply Germany). The giomer was placed in the cavity using the incremental oblique layers technique, each layer of maximum $2 \mathrm{~mm}$. The layers were light-cured $20 \mathrm{sec}$ each before applying the next one. Finishing and polishing of the restorations was done using Super Buffs disks from Shofu (Kyoto, Japan). The teeth were thermocycled 500 times in a $5^{\circ} \mathrm{C}-55^{\circ} \mathrm{C}$ water baths. Each cycle lasted $60 \mathrm{sec}$. This is an artificial aging method according to the ISO /TS11405:2003 [29]. After that the teeth were bloated dried with paper towels and the roots were sealed with composite resin. The exterior surface of the teeth was isolated using two layers of nail varnish on all their surface except $1 \mathrm{~mm}$ around the restoration. All samples were then immersed in $2 \%$ methylene blue solution for 24 hours. After rinsing the dye under running water the teeth were dried and embedded in methyl methacrylate and sectioned longitudinally in slices of $1 \mathrm{~mm}$ through both restorations using a diamond saw (Isomet 1000, Buehler,USA) under water cooling system [30]. Each slice was examined at optical microscope and scores were assessed for the dye penetration along the restoration /tooth interface according to the ISO standards: 0-no dye penetration; 1-dye penetration till $1 / 2$ of the wall examined; 2-dye penetration to the full depth of the wall; 3-dye penetration reaches the axial wall. 
5. Scanning electron microscopy (SEM). The morphology of the pre-reacted glass particles and of the fracture morphology of giomers was determined by SEM (JEOL, JSM 5510 LV) operated at $30 \mathrm{kV}$. The samples were prepared by dispersing a thin layer of the glass powders on a carbon tape and coated with $8 \mathrm{~nm}$ gold evaporated in an argon atmosphere (Sputter Coater Agar) prior to analysis

6. Atomic force microscopy. The AFM investigation of the surfaces of the tooth slice was done using the scanning probe microscope, AFM, JEOL 4210 equipment operating in the intermittent contact, also known as tapping mode [31-34]. The cantilever used was triangular, with a tip made from silicon nitride (NSC11, Micromasch Co. Estonia). The probe (tip) was on the cantilever, oscillating with a resonant frequency in the range of 260-330 $\mathrm{kHz}$ and having a spring constant of $48 \mathrm{~N} / \mathrm{m}$. Both a low scanning rate, $1 \mathrm{~Hz}$, and a higher rate, in the range 2-6 Hz, were used, in order to detect possible scanning artifacts or those resulting from the sample preparation. The AFM images consist of multiple scans displaced laterally from each other in $Y$ direction, the resolution being $512 \times 512$ pixels. An adequate low pass filtering was performed to remove the statistical noise without loss in the structural features of the material. All AFM experiments were carried out under ambient laboratory temperature conditions (about $20^{\circ} \mathrm{C}$ ). All the images were processed according to standard AFM proceeding.

\section{ACKNOWLEDGEMENTS}

This work was supported by two grants of the Romanian National Authority for Scientific Research and Innovation, UEFISCDI, project PN-IIIP2-2.1-PED-2016-1936 and project PNIII-P2-2.1-PED-2016-1907.

\section{REFERENCES}

1. M.C. Sunico, K. Shinkai, Y. Katoh, Operative Dentistry, 2005, 30, 282.

2. T. Itota, T.E. Carrick, M. Yoshiyama, J.F. McCabe, Dental Materials, 2004, 20, 789.

3. H. Ede Gonzalez, A.U. Yap, S.C. Hsu, Operative Dentistry, 2004, 29, 578.

4. K. Ikemura, F.R. Tay, T. Endo, D.H. Pashley, Dental Materials, 2008, 27, 315.

5. J.F. McCabe, A. Walls, "Applied Dental Materials", ninth edition, Blackwell Publishing Ltd., Singapore, 2008.

6. R.M. Carvalho, J.C. Pereira, M. Yoshiyama, D.H. Pashley, Operative Dentistry, 1996, 21, 17.

7. I.A. Mjör, Acta Odontologica Scandinavica, 1997, 55, 58.

8. I.A. Mjör, Operative Dentistry, 1985, 10, 88.

9. V. Qvist, J. Qvist, I.A. Mjör, Acta Odontologica Scandinavica, 1990, 48, 305. 
I. HODISAN, C. PREJMEREAN, I. PETEAN, D. PRODAN, T. BURUIANA,

L. COLCERIU, L. BARBU-TUDORAN, M. TOMOAIA-COTISEL

10. A.H. Tjan, D.E. Tan, Quintessence International, 1991, 22, 565.

11. M.J. Taylor, E. Lynch, Journal of Dentistry, 1992, 20, 3.

12. I. Yavuz, H. Aydin, Biotechnology and Biotechnological Equipment, 2005, 19, 181

13. J.B. De Almeida, J.A. Platt, Y. Oshida, B.K. Moore, M.A. Cochran, G.J. Eckert, Operative Dentistry, 2003, 28, 453.

14. F.M de Goes, M.A. Montes, Journal of Dentistry, 2004, 32, 391.

15. B. Karagenç, N. Gençoglu, M. Ersoy, G. Cansever, G. Külekçi, Oral Surgery, Oral Medicine, Oral Pathology, Oral Radiology, and Endodontology, 2006, 102, 110.

16. C. Prejmerean, D. Prodan, M. Vlassa, M. Streza, T. Buruiana, L. Colceriu, V. Prejmerean, S. Cuc, M. Moldovan, Measurement Science and Technology, 2016, 27, 124008.

17. C. Prejmerean, M. Moldovan, C.M. Petrea, D. Prodan, L. Silaghi-Dumitrescu, E. Vasile, G. Furtos, S. Boboia, R. Silaghi-Dumitrescu, Materiale Plastice, 2011, 48, 279.

18. A. Abo El Naga, Journal of American Science, 2012, 8, 27.

19. B.M. Owens, W.W. Johnson, E.F. Harris, Operative Dentistry, 2006, 31, 60.

20. C.E. Dörfer, H.J. Stachle, M.W. Wurst, H. Duschner, T. Pioch, European Journal of Oral Science, 2000, 108, 346.

21. C. Prati, L. Tao, M. Simpson, D.H. Pashley, Journal of Dentistry, 1994, 22, 49.

22. K. Derhami, P. Coli, M. Brännström, Operative Dentistry, 1995, 20, 100.

23. A. Thylstrup, S.A. Leach, V.Quist, "Dentine and Dentine Reactions in the Oral Cavity", Eds., Inform. Print. Ltd., Oxford, 1987, p. 17.

24. S. Habelitz, M. Balooch, S.J. Marshall, G. Balooch, G.W. Marshall, Journal of Structural Biology, 2002, 138, 227.

25. L.E. Bertassoni, G.W. Marshall, M.V. Swain, Micron, 2012, 43, 1364.

26. X. Zheng, H. Pan, Z. Wang, H. Chen, Journal of Microscopy, 2011, 241, 162.

27. M.B. Lopes, M.A. Sinhoreti, A. Gonini Jr., S. Consani, J.F. McCabe, Brazilian Dental Journal, 2009, 20, 279.

28. T. Buruiana, M. Nechifor, V. Melinte, V. Podasca, E.C. Buruiana, Journal of Biomaterials Science Polymer Edition, 2014, 25, 749.

29. International Organization for Standardization (ISO). "Dental materials-testing of adhesion to tooth structure", ISO/TS 11405: 2003 (Edition).

30. S. Deliperi, D.N. Bardwell, C. Wegley, M.D. Congiu, Operative Dentistry, 2006 , 31, 227.

31. C. Prejmerean, M. Tomoaia-Cotisel, E.Vasile, G. Furtos, L. Pop, M. Moldovan, I. Petean, International Journal of Nano and Biomaterials, 2011, 3, 344.

32. G. Tomoaia, O. Soritau, M. Tomoaia-Cotisel, L.-B. Pop, A. Pop, A. Mocanu, O. Horovitz, L.-D. Bobos, Powder Technology, 2013, 238, 99.

33. M. Tomoaia-Cotisel, A. Tomoaia-Cotisel, T. Yupsanis, G. Tomoaia, I. Balea, A. Mocanu, Cs. Racz, Revue Roumaine de Chimie, 2006, 51, 1181.

34. O. Horovitz, G. Tomoaia, A. Mocanu, T. Yupsanis, M. Tomoaia-Cotisel, Gold Bulletin, 2007, 40, 295. 